\title{
PEMAHAMAN TREN SAAT INI SEBAGAI LANGKAH AWAL PENGUATAN NILAI-NILAI PANCASILA
}

Kartoli, Helda Risma

Universitas Pertahanan, Bogor, Indonesia

Email: kartoli.cato@gmail.com

\begin{abstract}
It is inevitable that Pancasila has become a unifier and guide to the life of the nation and state. In line with the dynamics of the era, of course, in its application needs continuous efforts in its adjustment and strengthening. For this reason, understanding the current situation and conditions is important to be a concern. This paper tries to explain the tendency of the current situation and conditions in the context of evaporation of the Pancasila values. The related literature study was used by the autor to compile the main idea points referring to the current situation and conditions and the need for a relevant mindset to contemporary times without losing the essence of strengthening the values of Pancasila. It was hoped that this paper may be a contribution of thought for stakeholders in relation to efforts to strengthen Pancasila as a unifying philosophy and life guide for elements of the Republic of Indonesia.
\end{abstract}

Keywords: Pancasila; age trend; value reinforcement; relevance; descriptive exposure.

Abstrak. Sudah tidak dapat dipungkiri bahwa Pancasila telah menjadi pemersatu dan panduan kehidupan berbangsa dan bernegara. Sejalan dengan dinamika perkembangan jaman, tentu dalam penerapannya perlu upaya berkelanjutan dalam penyesuaian dan penguatannya. Untuk itu, pemahaman terhadap situasi dan kondisi berjalan penting untuk menjadi perhatian. Tulisan ini mencoba memaparkan kecenderungan situasi dan kondisi saat ini dalam konteks penguapan nilai-nilai Pancasila. Kajian pustaka terkait digunakan penulis untuk merangkai pokok-pokok pikiran merujuk kepada trend situasi dan kondisi berjalan dan perlunya pola pikir yang relevan dengan masa kontemporer tanpa menghilangkan esensi penguatan nilai-nilai Pancasila. Harapannya adalah tulisan ini dapat menjadi sumbangsih pemikiran bagi pihak terkait dalam kaitannya dengan upaya penguatan Pancasila sebagai falsafah pemersatu dan pedoman kehidupan elemen dari NKRI.

Keywords: Pancasila; kecenderungan jaman; penguatan nilai; relevansi; paparan deskriptif.

Permalink/DOI: https://doi.org/10.15408/mimbar.v37i1.17825 


\section{Pendahuluan}

Secara retrospektif, sudut pandang dan penerapan Pancasila juga dapat dikembangkan mengikuti dinamika perkembangan jaman sampai saat ini. Sebagai ideologi Negara Kesatuan Republik Indonesia (NKRI), Pancasila mengandung dua hal, yaitu sebagai pemersatu (Ligatur) dan penuntun pada kondisi yang dinamis (Leitstar). Secara intrinsik, persatuan merupakan salah satu esensi Pancasila. Hal tersebut tertera pada Sila Persatuan Indonesia. Sila tersebut pada dasarnya menjelaskan bahwa Indonesia, dengan dasar negaranya Pancasila, bertujuan untuk mencapai persatuan sebagai bangsa karena didorong oleh nasib penderitaan yang sama dan mengikat individu/kelompok pada tanah air Indonesia.

Tujuan tersebut memiliki sifat preventif yang besar dalam mencegah dari sifat Chauvinistis (Midhio, 2019). Selanjutnya, keempat sila yang lain menjadi penuntun kehidupan berbangsa bagi segenap elemen NKRI. Hanya saja, dalam penerapannya isu terhadap aspek pertama lebih menjadi perhatian saat ini.

Sejalan dengan perkembangan globalisasi saat ini, tidak dapat dipungkiri salah satu pengaruhnya adalah menyebabkan degradasi nilai-nilai Pancasila (Baureh, 2018). Salah satu indikasinya adalah dengan berkembangnya ilmu dan teknologi, khususnya teknologi informasi dan komunikasi (TIK), dan dunia bisnis, mempengaruhi cara hidup penduduk saat ini. Dilain sisi, hal ini belum disertai dengan kesadaran dan pemahaman yang mendukung dalam pemanfaatannya. Salah satu akibatnya, muncul kecenderungan degradasi tata nilai kehidupan di kalangan generasi saat ini. Lebih detail, dengan maraknya penggunaan gawai yang berlebihan sehingga Generasi Milenial dan Z lebih cenderung mengonsumsi barang-baik informasi atau barang/jasa secara literal— sehingga memunculkan bibit degradasi Pancasila.

Lebih lanjut, permasalahan intinya bukan hanya terletak pada penggunaan teknologi yang berlebihan yang notabene merupakan efek samping dari perkembangan jaman. Permasalahan lebih terletak pada pemahaman terhadap ruang bebas yang disebut sebagai tren dinamika perkembangannya. Seiring perkembangan zaman, tren juga berubah dan evolusi ini menuntut permintaan khusus mengenai penguatan nilai-nilai Pancasila. Singkatnya, penguatan nilai-nilai Pancasila sebagai ideologi bangsa juga memerlukan wajah baru yang lebih relevan dengan masa kontemporer tanpa menghilangkan tujuannya sebagai pedoman hidup berbangsa.

Pemahaman terhadap bentuk penguatan nilai-nilai Pancasila sejalan dinamika perkembangan jaman menjadi penting di sini. Bagaimana menggali sudut pandang generasi milenial sampai $Z$ terhadap nilai kehidupan berbangsa sejalan dengan tren saat ini dan bagaimana bentuk penyematan dan penguatan nilai-nilai Pancasila dengan nuansa yang mutakhir perlu untuk menjadi perhatian. Hal ini memerlukan pemikiran yang out of the box. Tulisan ini menguraikan mengapa tren menjadi medium yang penting dan beberapa analisis global untuk mengarahkan pada kesimpulan bahwa Pancasila memerlukan tren yang baru tanpa mengubah esensinya sebagai pedoman kehidupan bagi Bangsa Indonesia. Tujuannya adalah untuk menjelaskan secara deskriptif berdasarkan kajian literatur terkait ruang antara tren antar generasi saat ini. Harapannya adalah tulisan ini dapat menjadi sumbangsih pemikiran bagi pihak terkait dalam kaitannya dengan upaya penguatan Pancasila sebagai falsafah pemersatu dan pedoman kehidupan elemen dari NKRI. 


\section{Pembahasan}

Seusai Post-Modern dengan klaim relativitasnya akan kebenaran, kini fenomena sosial diisi oleh Post-Truth (Pasca-Kebenaran). Keduanya memiliki esensi untuk berbicara, memberikan klaim, bahkan sikap terhadap hal yang disebut dan dianggap sebagai suatu 'kebenaran'. Seperti dijelaskan oleh Harvey (1989), pemahaman tentang 'kebenaran' mengalami pergeseran paradigma dari masa ke masa. Ketika di era Modernisme, 'kebenaran' disandarkan dari segala hal mencakup material maupun empiris. Berbeda hal dengan Pasca-Modernisme yang menyandarkan 'kebenaran' pada relativitas—sebab hal yang disebut atau dianggap sebagai yang benar akan berbeda pada setiap individu.

Di era globalisasi yang semakin canggih dan sarat akan keterbukaan informasi, Pasca- Kebenaran mengisi ruang-ruang publik, baik daring dan luring, sosial maupun politik. Esensi dari Pasca-Kebenaran adalah mendominasinya subjektivitas dari individu/kelompok untuk menentukan apa yang disebut dan diklaim sebagai 'kebenaran'. Hal tersebut menimbulkan permasalahan karena bias-bias dari PascaKebenaran juga berada di ruang publik — bahkan sampai ke ranah politik praktis-yang seharusnya memiliki batas-batas khusus untuk mendudukkan permasalahan-permasalahan privat. Fenomena ini diperparah dengan era keterbukaan informasi yang masif. Namun, esensi dalam era Pasca-Kebenaran yakni permainan emosi manusia untuk menggiring dan digiring dalam suatu wacana tertentu.

\section{Post-Truth (Pasca-Kebenaran)}

Pada dasarnya, "Post-Truth" sebagai terminologi sudah mulai dikenal pada tahun 1992 dari esai The Government Lies yang diterbitkan di majalah The Nations yang ditulis oleh Steve Tesich. Dalam esai tersebut, Tesich berangkat dari dua peristiwa sejarah, yaitu Perang Watergate dan Perang Teluk. Baginya, Pasca-Kebenaran merupakan kondisi di masyarakat luas yang lebih nyaman untuk hidup di dalam kebohongan dan fakta-fakta yang dikaburkan. Kondisi inilah yang menjadi pijakan analisisnya mengenai Pasca-Kebenaran (Kreitner, 2016). Kreitner (2016) menjelaskan bahwa dalam Perang Teluk, pemerintah Amerika Serikat memainkan emosi masyarakatnya melalui pernyataan tegas dari Duta Besar AS untuk Irak yang bersandar pada premis bahwa perang yang (akan) terjadi tidak dapat dihindari. Namun, di saat bersamaan, AS di masa itu juga menarasikan demokratisasi, kebanggaan nasionalisme (yang ekspansif), dan juga melarang kebebasan pers internasional untuk meliput peperangan tersebut. Pada akhirnya, masyarakat AS membentuk persepsi ancamannya tersendiri dari Amerika Utara sampai Kuwait.

Jika diamati lebih dalam, ketika Pasca- Kebenaran semakin berevolusi dan berkelindan dengan perkembangan teknologi di era digital, hal tersebut akan bermuara kepada metode Weaponizing Information. Umumnya, metode ini digunakan untuk kepentingan-kepentingan politis melalui beberapa tahapan secara konseptual, yaitu melakukan konstruksi pemikiran, pencitraan, dan kedua tahapan tersebut bermuara pada misinterpretasi (untuk konteks Indonesia mengenai Pancasila).

Di era sekarang ini, Pasca-Kebenaran berangkat dari dua fenomena; Brexit dan naiknya Donald Trump ke tampuk pemerintahan AS. Di saat bersamaan, banjir informasi ditunggangi dengan tersebarnya hoaks yang lebih dominan dibanding fakta-fakta objektif di khalayak. Hal tersebut juga 
mempengaruhi tren media (Syuhada, 2018). Tahapan konstruksi pemikiran menjelaskan secara intrinsik bahwa terdapat narasi-narasi lain dan ruang-ruang alternatif, dalam hal ini platform media sosial, yang mendominasi opini publik karena dianggap sebagai platform media sosial yang memiliki ruang kebebasan berpendapat yang lebih luas dibanding platform lainnya.

Dalam platform yang luas dan bebas tersebut, aktor-aktor yang memiliki pengaruh memulai narasi politik di media sosial. Hasil dari konstruksi pemikiran tersebut menggiring masyarakat pada misinterpretasi terhadap status quo di suatu negara. Pola kontemporer seperti ini, bagi pegiat Demokrasi Liberal, disebut Populisme Baru. Secara objektif, Populisme Baru merupakan hasil dari sistem demokrasi itu sendiri yang menyediakan ruang terbuka bagi seluruh lapisan masyarakat. Dalam konteks ini, elit dan rakyat (populist) (Mudde \& Kaltwasser, 2017).

Mudde and Kaltwasser (2017) menjelaskan bahwa pola kontemporer seperti ini, bagi pegiat Demokrasi Liberal, disebut Populisme Baru. Secara objektif, Populisme Baru merupakan hasil dari sistem demokrasi itu sendiri yang menyediakan ruang terbuka bagi seluruh lapisan masyarakat. Dalam konteks ini, elit dan rakyat (populist). Permasalahannya adalah dengan silang-sengkarutnya Populisme Baru dan juga hoaks, pelan-pelan pemikiran publik terdegradasi mengenai Pancasila.

Pengalaman traumatis bangsa Indonesia akan devide et impera harus menjadi bahan retrospeksi bangsa Indonesia. Politik adu domba oleh Belanda tersebut lebih mudah dilakukan karena bangsa Indonesia pada masa itu belum memahami konsepsi kebangsaan dengan komprehensi. Lagi, keberagaman dan perbedaan dipandang sebagai tipologi kawan- lawan.

Rekonstruksi semangat nasionalisme pada saat ini tidak bisa lagi dipandang dan dibawa dengan pendidikan hapalan saja. Sabab pemahaman tenang konsepsi negara kesatuan, seturut Yudi Latif, harus kongruen dengan sifat dan watak bangsa Indonesia (Latif, 2016). Ketika Pancasila dilanda gelombang Pasca- Kebenaran dan melahirkan bibit-bibit anti- Pancasila, maka bangsa Indonesia harus memang pembangunan karakter bangsa sebagai sesuatu yang penting namun pada ruang yang luas dan tidak kaku—bukan berarti permisif.

Dengan begitu, sikap toleransi memang harus menjadi filter dalam urusan kehidupan bernegara dan berkebangsaan. Sebab, tanpa sikap tersebut bangsa Indonesia hanya dihantarkan pada sifat permisif atau intoleran. Keluwesan dalam penanaman pemahaman Pancasila sebagai dasar negara juga sangat diperlukan untuk menyambut Revolusi Industri 5.0 karena mengarah pada kualitas sumber daya manusia, bukan lagi teknologi. Barangkali kita harus melihat konsepsi umum untuk mencegah simplifikasi dalam mehami gejolak yang ada. Misal, mengapa liberalisme dengan narasi kebebasan individunya dianggap begitu penting dibanding Pancasila yang lebih universal? Kebanyakan publik memaknai liberalisme sebagai tren.

Dengan demikian, tren yang dianggap publik (terlebih millennial) adalah hal yang harus diikuti, memiliki kapasitas khusus sebagai sarana penamanan nilai-nilai Pancasila yang bermuara kepada pembentukan karakter bangsa, nasionalisme, semangat bela negara, dan wawasan kebangsaan. Secara teoretik dan praktis, hal tersebut dapat dilakukan sebagai sikap atau respon dalam menyikapi ancaman terhadap Pancasila. Singkatnya, dengan mengedepankan pendekatan soft-power. 
Tren sebagai ruang bebas harus diisi dengan nalar kritis mengenai Pancasila. Penggunaan ruang tersebut dapat dilihat pada pra-1945, 1945-Reformasi. Amatan retrospektif ini bukan berarti mengembalikan Indonesia pada masa para Reformasi. Namun, menjadi pijakan untuk melakukan amatan mendalam.

Pada masa 1945, Indonesia diisi dengan semangat Pancasila dan semangat pada masa itu tidak sekadar diterima dengan hitam-putih saja. Namun, kondisi kausalitas pada masa itu harus dilihat dan memunculkan pertanyaan, mengapa pada terdapat dikotomi yang kontras antara era 1945-1990an dan pada masa kontemporer.

Pertanyaan tersebut mengarah pada pergolakan tren dan bagaimana Pancasila dapat mengisi ruang bebas tersebut, baik di media sosial atau pada kehidupan nyata bermasyarakat. Jika dihadapkan pada permasalahan kiwari/kekinian, lahirnya Undang-Undang Pengelolaan Sumber Daya Nasional (UU PSDN) Tahun 2019 yang berkaitan dengan Bela Negara memiliki relevansi dengan tren yang memengaruhi pola pikir masyarakat. Jika pada era Pra-Reformasi tren akan dianggap sesuai zaman jika menerapkan budi luhur, sementara dengan masifnya arus informasi pada masa Reformasi tren tersebut dipertanyakan, maka diperlukan restrukturisasi pada program-program berkaitan.

Disahkannya UU Bela Negara dan UU PSDN menjadi poin sentral untuk mengisi tren tersebut. Tujuannya adalah bagaimana menerapkan dan menguatkan nilai-nilai Pancasila pada masa kiwari dan hal itu dianggap sangat relevan dengan zaman. Penerapan dan penguatan nilai-nilai Pancasila dengan menggunakan medium tren sebagai sarananya bukan sekadar melanggengkan eksistensi negara dan pemerintah, tetapi mengarah pada pembumian nilai-nilai Pancasila. Relevansi tersebut dapat dihadapkan pada latennya ekstremisme, hoaks, dan pernyataan- pernyataan publik dari para stakeholder, baik dari kelompok kepentingan dan pemerintah.

\section{Penguasaan Tren sebagai Jalan Revolusi Pancasila}

Secara etimologis, terminologi "Revolusi" berasal dari ranah ilmu eksakta atau natural science. Istilah tersebut memiliki arti "untuk kembali" atau "berulang kembali". Untuk pertamakalinya istilah ini digunakan oleh Nicolaus Copernicus dalam bukunya De Revolutionibus Orbium Coelestium yang dipandang sebagai penanda revolusi paradigmatik dalam ranah sains yang menggeser keyakinan manusia mengenai pusat alam semesta dari geosentrisme ke heliosentrisme. Kemudian, istilah ini kembali bergeser padanan aslinya ketika Thomas Kuhn mendefinisikannya sebagai perubahan dalam susunan keyakinan saintifik atau dalam paradigma (Latif, 2016, hal. 20-22).

Revolusi diartikan sebagai kebaruan dari kesinambungan. Secara historis, peradaban dunia mengalami beberapa revolusi besar modern dengan mengusung ideologinya masing-masing. Terlebih lagi dalam bidang politik, seperti Revolusi Amerika Serikat pada tahun 1776 yang kemudian disusul oleh Revolusi Perancis pada tahun 1789. Pada dasarnya, revolusi secara etimologis dipahami sebagai suatu perubahan yang ramah, tetapi tragedi Revolusi Perancis dan pada abad ke-19 menyusul Revolusi 1848 yang menjadikan The Communist Manifesto sebagai dasarnya, membuat terminologi ini memiliki muatan pejoratif, bahkan ofensif. Terlepas dari tragedi sejarah tersebut, revolusi secara esensial tidak dipandang 
dari penggulingan status quo-nya atau percepatannya saja, tetapi esensi dari revolusi terletak pada kebaruannya (newness) yang mampu mentransformasi dunia lama ke dunia baru (Latif, 2016, hal. 32).

Lebih lanjut Latif (2016) menjelaskan, meskipun revolusi Pancasila yang dimaksud bukan berarti perubahan-perubahan mendasar seperti ideologi bahkan sila-sila dari Pancasila. Pancasila sudah tetap (established) sebagai ideologi. Pembahasan ideologi tersebut dapat ditarik dari analisis sejarah pada era founding fathers negara Indonesia. Soekarno mengistilahkan pandangan hidup (Weltanschauung) dalam lanskap Pancasila sebagai ideologi. Jika dilihat, pada masa itu merupakan masa perdebatan antara ideologi- ideologi: 1) Hitler dalam membangun narasi Weltanschaunng berlandaskan national- sozialistische Weltanschauung; 2) Pendirian Soviet berlandaskan Marxistische Historich Materialistische Weltanschaunng; 3) Jepang (Nippon) mendirikan negaranya di atas Tenno Koodo Seisin; 4) Ibnu Saud mendirikan Arab Saudi di atas satu Weltanschaunng dan bahkan satu agama, yaitu Islam; 5) Cina mengisi kemerdekaannya oleh Sun Yat Sen yang berdasarkan Weltanschaumng San Min Chu I; Mintsu, Munchuan, Minshen: Nasionalisme, Demokrasi, dan Sosialisme.

Dari sekian banyak—secara general — ideologi tersebut, Indonesia sudah menetapkan Pancasila sebagai dasar konsepsi bersama dalam kehidupan berbangsa dan bernegara, atau ideologi dan hal tersebut sudah tetap. Latif (2016) menerangkan Revolusi Pancasila memiliki logika dan teori tersendiri, yaitu: 1) Revolusi dilakukan secara berkesinambungan; 2) Harus dipimpin oleh orang-orang yang revolusioner dan bukan yang anti revolusi (Pancasila); 3) Didasari oleh teori revolusioner yang kemudian menyebabkan gerakan revolusioner; 4) Dijalankan dari atas ke bawah, terutama kepada kalangan elit; 5) Dilakukan secara bertahap.

Dalam konteks permasalahan kekinian, hal ini memiliki relevansi bahwa penggunaan tren sebagai medium penguatan (bukan sekadar mempromosikan Pancasila) merupakan tindakan yang revolusioner pada era Pasca-Kebenaran ini. Hal itu dikarenakan melakukan suatu pembaharuan dalam berbicara mengenai Pancasila agar mencapai ranah pemikiran kritis dan dengan secara tidak langsung membangun kecenderungan yang lebih segar dalam berkehidupan Pancasila. Singkatnya, membuat Pancasila diminati secara revolusioner adalah tujuan yang juga mesti dicapai.

\section{Tren Dari Negara Lain}

Tren atau kecenderungan dalam poin pembahasan ini tidak berbicara mengenai paham-paham dari luar Indonesia, tetapi bagaimana negara-negara lain juga berbicara mengenai penguatan ideologinya dalam bahasa yang berbeda. Bahasa tersebut berangkat di luar nuansa-nuansa poltik negara. Dalam ranah strategi, menjadikan Pancasila sebagai tren adalah hal yang tepat dikarenakan negara tidak mampu menerapkan nilai-nilai dasar Pancasila dan Bela Negara sekadar menggunakan Pusat Pelatihan Bela Negara. Secara global, kita dapat melihat beberapa negara yang menggunakan tren untuk melanggengkan nasionalisme melalui sarana non-negara.

Sebagai contoh, kampanye politik Amerika Serikat dengan “American First” oleh Donald Trump bukan semata narasi politik yang datang tanpa fondasi sumber daya AS. Sejak Perang Dingin, AS menggunakan Hollywood sebagai media Diplomasi Budaya. Salah satu temuan mengenai perfilman AS sebagai corong promosi nasionalisme adalah terbentuknya beberapa kondisi, seperti gambaran 
transnasional mengenai AS, nilai-nilai, bahkan sampai ranah etnografik (Peters, 2015). Konsekuensi dari kondisi tersebut berimbas pada ranah kebijakan. Pada konteks ini, pemerintah AS kerap mengesahkan kebijakan- kebijakan yang berpengaruh kepada masyarakat atau bangsa dan juga pesan-pesan atau diskursus media (Peters, 2015, hal. 334).

Dalam kasus ini, AS berbicara mengenai nasionalismenya dalam bahasa yang berbeda dengan mengendarai film sebagai sarana untuk mendominasi tren. Pada akhirnya, akan menciptakan suatu kondisi yang memiliki muatan politis negara tanpa merasakan kehadirannya. Contoh lainnya adalah Korean $W$ ave. Tren satu ini merupakan hasil dari perpaduan antara sumber daya nasional Korea Selatan yang menggabungkan antara nasionalisme dan diplomasi budaya. Dalam sebuah literatur, mengatakan bahwa sebenarnya Korean $W$ ave (yang digemari para milenial secara global) merupakan penggabungan antara soft power dengan segala sumber daya nasional terkait.

Korean Wave atau Hallyu sudah berjalan lebih dari dua puluh tahun bahkan di ranah praksis presidensial sudah menjadi narasi kebijakan. Dalam hal ini, Korea Selatan sudah lama mengincar penguasaan tren untuk meningkatkan kapabilitas negaranya - termasuk konsepsi bersama dari negaranya. Hal itu dapat dibuktikan dengan meluasnya tren global mengenai Korea Selatan, baik segi budaya, etnografi, sejarah, politik, bahkan sosial-ekonominya (Kim, 2016). Di samping itu, jumlah minat akan Korea (Selatan) meningkat dari tahun ke tahun. Howard (2013) memaparkan perkembangan minat budaya korea yang meningkat secara global terkait dengan penguatannya. Tentu, hal tersebut juga menginisiasi bahkan mendukung penuh penguatan nasionalisme Korea Selatan. Dalam konteks nasional Indonesia, penggunaan sarana-sarana non-pemerintah yang bernuansa dalam negeri memiliki kapabilitas untuk menggerakkan Pancasila. Dengan menggunakan strategi demikian, Pancasila berpotensi mengisi ruang kosong pada tren era kiwari ini. Dampaknya akan beragam, pada kasus tulisan ini, sekurangnya memiliki kapabalitas untuk mereduksi racun dari Pasca- Kebenaran.

\section{Penutup}

Pemaknaan Pancasila mengalami evolusi seiring dengan bermunculannya narasi-narasi antar generasi. Masifnya arus informasi menjadi peristiwa yang penting dicermati dikarenakan menggerus nilai-nilai Pancasila, walau pun tidak seluruhnya. Kompleksitas yang mengisi era pertentangan antara Baby Boomer dan Milenial—dan juga Z—harus dilihat dari refleksi kritis lintas generasi. Degradasi nilainilai Pancasila tersebut diperparah dengan masifnya buah-buah dari Pasca-Kebenaran dan narasi politik dengan tafsir bebas, bahkan liar, mengenai Pancasila. Dengan demikian, pandangan kritis untuk Pancasila berawal dari pendekatan retrospeksi mengenai tren. Sebab, tren mampu menggerakkan pola pikir masyarakat.

Akan tetapi, untuk berpartisipasi pada ruang bebas tren masyarakat tidak dapat dilakukan dengan kaku melalui narasi nasionalisme yang murni dari negara. Kaidah Bela Negara dan PSDN mampu untuk menjadi corong penguatan nasionalisme, dalam hal ini Pancasila, tanpa mengubah esensi dari pilar- pilar kebangsaan. Dengan mengisi tren — sehingga mendominasi untuk menarasikan Pancasilamenggunakan sarana yang bukan murni dari negara, maka hal tersebut dapat terlepas dari sentimen 
publik mengenai ruang bebas bernegara. Sehingga, tren dapat dijadikan sarana yang buka sekadar agitasi, tetapi juga respon aktif terhadap penggerusan dan tergerusnya nilai-nilai Pancasila.

Penguasaan tren tidak dapat dipaksakan melalui sekadar dan hanya melalui pintu negara saja. Pelibatan stakeholder non-negara namun dalam negeri memiliki kapabilitas yang tinggi sebagaimana yang dilakukan Amerika Serikat melalui Hollywood dan Korea Selatan melalui Korean Wave atau Hallyu. Dengan demikian, Indonesia tidak hanya mencapai revolusi Pancasila, tetapi penguatan nilai-nilai Pancasila tanpa membebankan kepada Milenial dan Generasi Z (atau bahkan generasi selanjutnya) mengenai degradasi nilai Pancasila.

\section{Daftar Pustaka}

Midhio, I. W. (2019). Pancasila sebagai Pemersatu Bangsa.Pembekalan Mahasiswa Baru Universitas Pertahanan Indonesia. Universitas Pertahanan.

Baureh, M. G. (2018). Dampat Yuridis Degradasi Nilai-Nilai Pancasila dalam Kehidupan Sosial di Era Millenial. SINTESA.

Harvey, D. (1989). The Condition of Postmodernity: An Enquiry into the Origins of Cultural Change. Oxford: Blackwell.

Howard, K. (2013). The Foundation of Hallyu-K- Pop's Coming of Age.

Kim, T. Y. (2016). Cultural policy in the Korean Wave: An analysis of cultural diplomacy embedded in presidential speeches. International Journal of Communication, 10, 21.

Kreitner, R. (2016). Post-truth and its consequences: What a 25-year-old essay tells us about the current moment. The nation, 30.

Latif, Y. (2016). Pancasila Sebagai Norma Dasar Negara: Implikasinya Terhadap Perumusan Konstitusi. Makalah FGD Evaluasi Dan Proyeksi Pembangunan Hukum Nasional Dalam Rangka Penyusunan Dokumen Pembangunan Hukum Nasional Tahun.

Mudde, C., \& Kaltwasser, C. R. (2017). Populism: A very short introduction: Oxford University Press.

Peters, J. J. M. (2015). American Cinema as Cultural Diplomacy: Seeking International Understanding One Film at a Time. UCLA.

Syuhada, K. D. (2018). Etika Media di Era “Post- Truth”. Jurnal Komunikasi Indonesia, 75- 79. 